\title{
The Ancient Josefov Jewish Quarter in Prague: An Example of Urban Island
}

\author{
Domenico Chizzoniti, Gaia Preta, Luca Preis, Letizia Cattani and Monica Moscatelli \\ Department of Architecture, Built Environment, Construction Engineer (ABC), Politecnico di Milano, Milan 20133, Italy
}

\begin{abstract}
Our work concerns the study of the ancient Jewish Quarter Josefov, the urban center of Staré Město, in Prague. This Quarter represents a well-defined urban fact, recognizable within the fabric of the historic city. Over the centuries, it has influenced the shape of the city and has become one of the most important and characteristic elements through its structure and spaces, its geography and its architecture (the Synagogue or the Jewish cemetery). However, this quarter also represents a fundamental social fact for the city of Prague as it is born from and organized around a very strong and historically rooted cultural identity. This cultural identity is characterized by uses, social customs, and traditions of a Jewish community that has been part of the history of the city over the centuries, helping to create myths and legends around it. The aim of this research is to preserve and recognize that cultural identity, using a strategic vision that starts from the reconstruction of pieces of this cultural testimony via the recovery of small parts of the urban fabric in the center or on the edge of this urban island.
\end{abstract}

Key words: City and water, city center regeneration, structure of insularity, Jewish ghetto.

\section{Introduction}

"Prague can never have a true centre, for the simple reason that it isn't one but at least six cities, united by decree only in 1784" [1].

The urban morphology of the city of Prague is made of autonomous and complex events. These episodes that now build an apparently unified urban structure represent the area where mythological and legendary stories took place.

The "Moldava" River, crossing the city, represents the static element of those historical events and divides the first two fortified citadels that give rise to the urban history of the capital.

The hills of Hradčany and Petřin, with the Letná "Plateau", make up the western bank of the landscape, where the construction of Prague Castle started around the 19th century (Fig. 1).

On the opposite bank, at the east side, the slope of the land forms a natural amphitheater with the Vítkov hill. The second promontory originating from this

\footnotetext{
Corresponding author: Domenico Chizzoniti, prof. arch.; research field: architectural design. E-mail: domenico.chizzoniti@polimi.it.
}

shape is called Vyšehrad: it was here that a new fortification was erected (the Vyšehrad Castle). The construction of these two castles was to determine the future development of the settlements along the riverbank.

There is a deep connection between the history of the political and social events of the city of Prague and its unique geography. The history of the city cannot be read without the help of its geography, and the urban morphology is useless if it is not placed within a time frame.

A first topic that must be highlighted is the concept of the "autonomous settlements development". Our idea is that this concept is present throughout the history of Prague and appears to be closely related to the idea of insularity.

The ideal of insularity is tied to a geographical concept that recalls two inseparable notions of physical geography: insularity as related to a place completely surrounded by water, and the idea of insularity as compared to other areas. In the case of the city of Prague, the first meaning is partially verifiable while the second meaning has remained a 


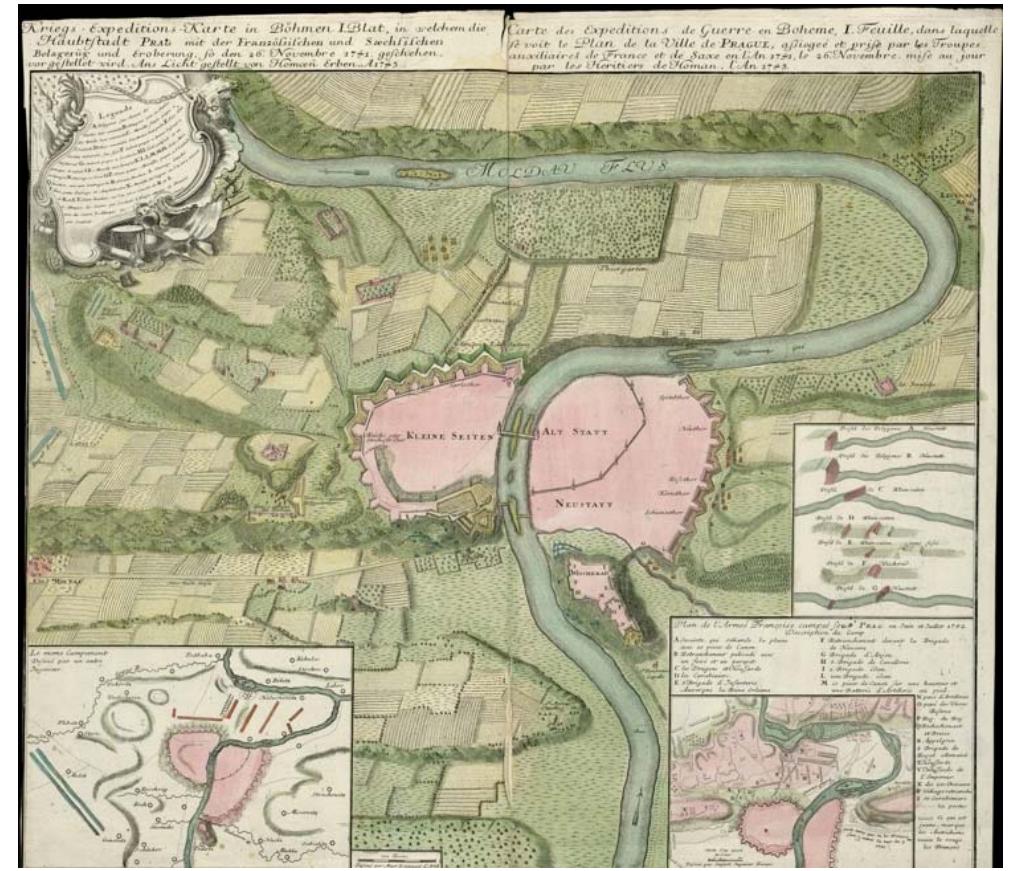

Fig. 1 Prague City Plan by Johann Baptist Homann, image taken from The Hebrew University of Jerusalem and The Jewish National and University Library, 1743.

rather persistent constant throughout its history.

This second definition of insularity is often adopted in its negative sense. In the case of this study, this term serves to amplify the meaning of island, defining areas whose isolation is no less acute but can indicate special or different identities compared to surrounding territories (or even situations that break or stop a certain behaviour or phenomenon).

On the other hand, it should be specified that the concept of island, while appearing very simple, is in fact quite complex. Further analysis reveals the multidimensionality of this term [2], which is itself a metaphor. Various studies have been devoted to the terminology of this word and the identification of possible interpretive paradigms.

The idea of insularity, therefore, does not correspond only to the definition of physical islands surrounded by water but also identifies both areas surrounded by different physical elements and social or cultural islands that differ from everything around them. These "islands" obtain identifying elements from this diversity [3].

In this paper, therefore, a definition of insularity is adopted that is fully part of the definition of spatial entities in general, whereby different combinations of physical and empirical data with how to make, narrate or describe the physical data (or even the interweaving of spatial data with its lived human experiences) are reflected in the various types of insularity.

As claimed by the "geographers of insularity", it is not only the physical data that define the structure of an insular territory, but rather human activities. Geographers insist on the notion of "insularity" understood as a "range of possibilities" of a territory, or a settlement to be constantly compared to something other than itself.

This expression of insularity has endured throughout the history of Prague, and in each case, the different islands of the City of Prague have played either a central role or one of marginalization. "Insularity" is, therefore, a relative notion. The urban structures under consideration in this work are not autonomous systems, but rather develop under the influence of broader economic, social and cultural trends, to which they show alternately open- or closed-minded "attitudes". In other words, what 
distinguishes the island - at least the island that is relatively small —is surprisingly not its "isolation", but its permeability from the exterior due to an open structure and fragile, vulnerable borders.

If the two castles constituted the most important elements of the fortified settlement, a third city (no less important than the first two, first recorded around the year 960), is located on the right bank of the "Moldava" River. This part of town attracted lively businesses that soon developed a market square, close to the princely court of Týn (with the rotundas of St John's and that of the Church of the Holy Cross), and is now the historical centre of Prague's Old Town: Stáre Město.

"... And it is not by accident that the north-west quadrant of the Staré Mésto would become the Jewish city, also known as Josefov (Josephstad, Josef Town) after Josef II who made it less segregated toward the end off the eighteenth century, though it would become a part of Prague itself only in 1850. Since 1942 it has, inevitably, been little more than a skeleton" [1].

"Dating from 1257, the much flatter Malá Strana (Kleineseite, Lesser Town), the area of houses and gardens below the Hradčany, is uniform in design because it was born as a piece from the ashes it had been reduced to by the Thirty Years' War" [1].

"On the high ground between StaréMěsto and Vyšehrad is NovéMěsto (Neustadt, New Town), the spacious new settlement decreed by Charles IV in 1348. The new walls enclosed existing quarters and uncultivated ground on such a scale that the horse market alone (now Václavské nàmestí, Wenzelsplatz, St. Wenceslas Square) could comfortably accommodate a small Tuscan town" (Fig. 2) [1].

Using the same logic, the Jewish city is to be recognized as today's Josefov neighbourhood; Malá Strana (1257), as part of the residential city, with gardens located under the Hradčany; the so-called Nové Město, the new town between Staré Město and Vyšehrad (1348).

Further out, there are other, smaller "Pragues", gradually incorporated into the urban structure such as Břevnov with its baroque monastery, founded in 993; Dejvice with its Stalinist hotel, documented since 1088; Smíchov with its popular brewery, known from 1406.

Towards the end of the 14th century, Prague is a city of European scale, with its own university and two

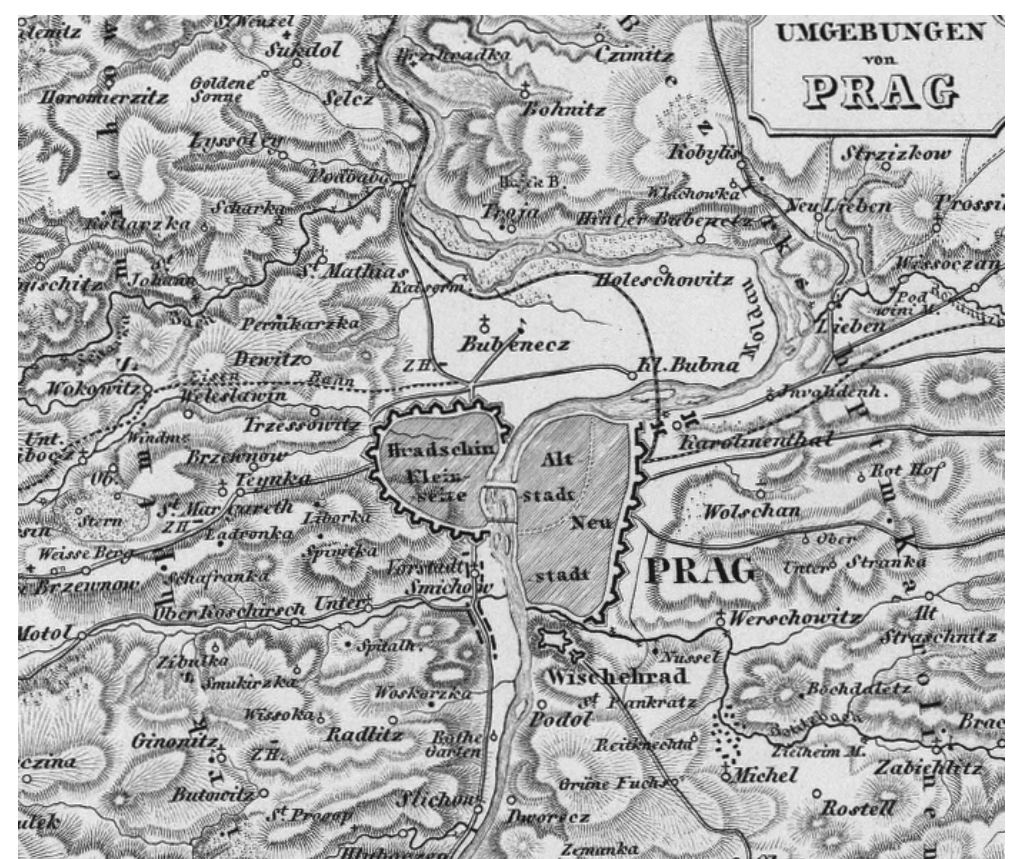

Fig. 2 Prague neighborhoods, according to Carl Ferdinand Weiland, image taken from the Geographisches Institute in Weimar, 1847-1856. 
castles, made up of five main administratively autonomous centres: Staré Město, Nové Město, Malá Strana, Hradčany, and Vyšehrad.

The Renaissance period would be characterized by large-scale renovations of Prague Castle, new designs of the fortifications, and a period of the splendour under Rudolf II, "the Habsburg who knew the Golem", before succumbing again to a period of conflict between the kings and Bohemians that would culminate in the famous battle of the "White Mountain" in 1618 (Fig. 3).

The main structure of the city is, at this point, made up of different realities that face one another but that do not ever consider one another, divided by the great river. This division appears to account for the "isolation" of the urban parts - an action that was at one time required of the historic fortifications, and that we later find in the introverted character of the giant ecclesiastic complexes built during the country's phase of catholicization.

The defeat of the Protestants by the imperial catholic forces, in fact, represents the first decisive battle in the Bohemian phase of the Thirty Years War. This violent "religious conversion", supported by the strong presence of the Jesuit order, had an impact on the city"s development program and its urban planning (Fig. 4).

In the last decades of the 17th and the 18th century, the Habsburgs, having definitively acquired Bohemia, proceeded with the renovation of Malá Strana.

The Baroque style began to take the place of the medieval roads of the city; new fortifications were built around Malá Strana and Nové Město and big religious buildings such as the Jesuit college "Klementinum" involved the destruction of large areas of Staré Město, just as the construction of the Valdstejn Palace came to occupy an important part of Malá Strana.

The year 1784 marks a new trend in the development of the city (compared to the fragmented history of the Bohemian capital), as it is the year of the unification of the four cities of Prague: Stare Město, Josefov, Nové Město, Malá Strana, Hradčany and Vyšehrad. The waterways between the Old Town and the new town were filled in, and in their place a tree-lined promenade was constructed. Urban development proceeded well over the historical boundaries of the city, and in 1821 Prague's first suburb-Karlín —was born.

The concept of "insularity" of Prague's various

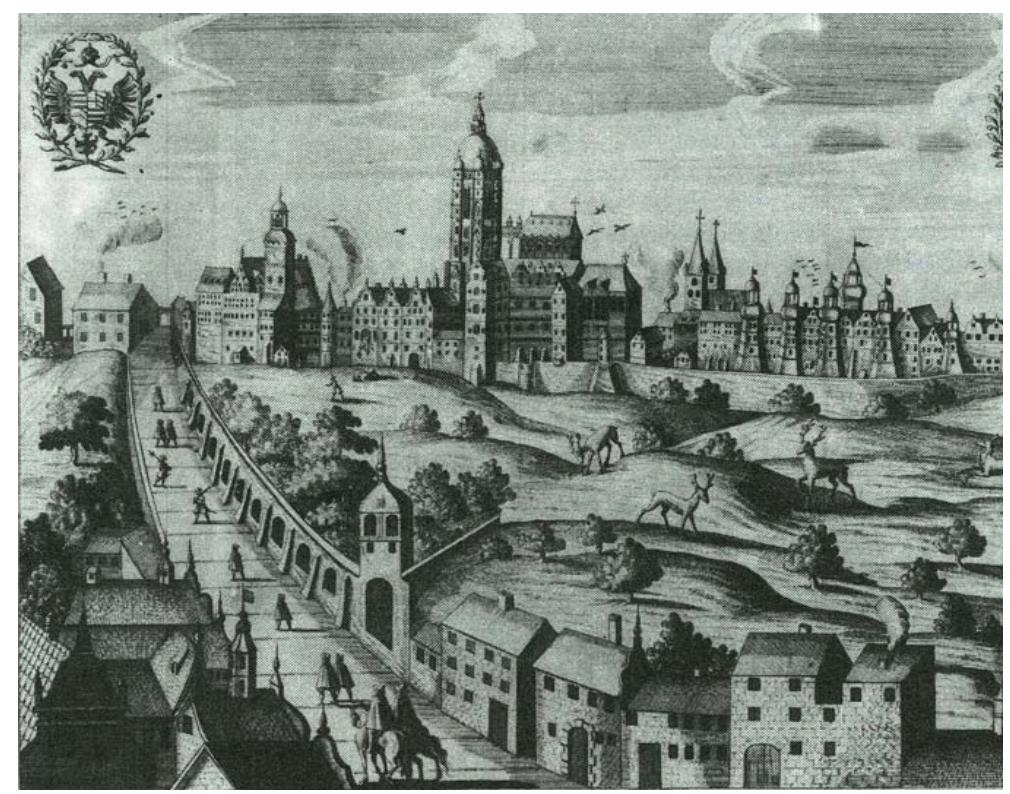

Fig. 3 Prague Castle by an anonymous author, according to F. Hoogenberg, image taken from the publication Civitates Orbis Terrarum, 1593. 


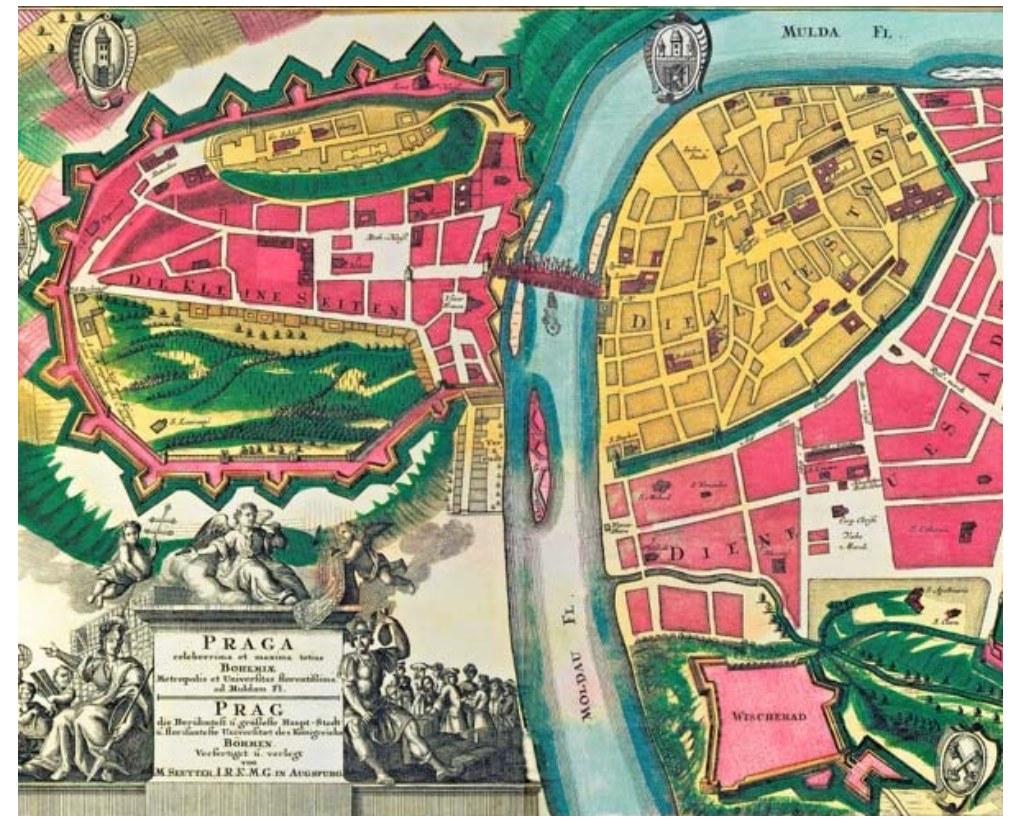

Fig. 4 Prague City Plan by Georg Matthäus Seutter, image taken from the Historical Institute of the Academy of Sciences of the CR, Prague, 1740.

realities is revisited in this work through a design method which is based on the redevelopment of urban space and existing monuments, with the aim of legitimizing the existence of these "urban islands" and reinforcing an urban and cultural identity.

\section{Ghetto Island and the Physiognomy of a Crossroad City}

The city of Prague has produced, throughout its history, a unique level of fascination in foreign visitors. "The fascination of Prague, the life of Prague has no end", says Ripellino in the final notes of his "Magic Prague" [4].

Many are the witnesses of its history, of its spells, the authors that describe the secret places, the magic of the alchemists, the legend of the Golem. So the city comes alive through the stories of Kafka, the meetings of Apollinaire or Kundera. Going from Chateaubriand, through the works of novelists such as Bohumil Hrabal, Gustav Meyrink, Jan Neruda, Vitezslav Nezval, Rainer Maria Rilke or the travelers' tales as Ingeborg Bachmann, Albert Camus, Paul Celan, W. G. Sebald.

Thus, within the city of Prague, different centers can be recognized, different "Pragues" that are not just physical places, but also invisible literary cities and historical cities that followed one other over time: from Charles IV, to Rodolfo Habsburg, up until more recent history and the new architecture of Jan Koterra.

The 20th-century architecture of Prague reflects scientific progress on one hand, while on the other, it reflects the deep social changes taking place in the late 19th and early 20th century. Czech Cubism, with some important architects as Josef Gocar, Pavel Janak, Oktar Novotny, Josef Chochol and others, tries to restore a unitary image of the city through the re-composition of the mythical places of its history.

The Josefor Ghetto is one of these places. It is a mythical place, an island in the archipelago of the cities of Prague, with its own shape, its own laws, and its own life at the center of the Old Town (Staré Město).

The story of this Jewish "island" in Prague is not very different from that of many other ghettos in which Jews were forced to live through the centuries.

If history still tells the tragic events of the Holocaust through the preservation of symbolic places such as the famous Cemetery, the Terezin Children 
Museum and the Široká Synagogue, which preserves the names of those deported to the death camps, the importance of Josefov for Prague also lies in its historical, cultural and social stratification. It lies in the memory of a mode of settlement that has been able to create values by way of a community - a community that still today gives a civil status to that place.

Originally, the Jewish quarter stood near the castle, and it was only in the 12th century that the Jews moved close to the Old Town Square in Staré Město, beginning the expansion of Josefov (Fig. 5).

The population density of the neighborhood was very high and its settlement structure was organized around a complex "ensemble", dense and labyrinth-like, formed not only by houses but also by commercial activities, big and small synagogues, healthcare services and one single not built open space: the Cemetery.

The total neighborhood area has never exceeded $93,000 \mathrm{~m}^{2}$ of extension, a rather small surface area compared to its population.

The history of European Ghettos is best known for the discriminations committed against the Jewish people. In Prague, from 1592 onwards, this discrimination decreased thanks to the intervention of Rabbi Löw, who had a strong hold on Rudolf II (especially due to his knowledge of the Kabbalah and alchemy).

In 1850, the Jewish Ghetto gained constitutional value, and officially became part of the Prague system of autonomous cities with the name Josefov, or Josefstadt in German, in honor of Emperor Joseph II, who, starting from 1784 , had promoted a policy of discrimination reduction.

In 1893, the Ghetto underwent a remarkable transformation of its morphological structure: most of the historical buildings were destroyed, and were replaced with new structures in the Secese style, a particular variation of the Art Nouveau style in Prague (Fig. 6).

This change was somewhat controversial, even if many Jews had already begun to move to other parts of the city. As Franz Kafka wrote, "Today we walk through the old streets of the city rebuilt but our steps are 'unsteady (...)' Our heart does not know anything about the restoration carried out (...) The old Jewish quarter within us is more real than the new hygienic town around us" [5].

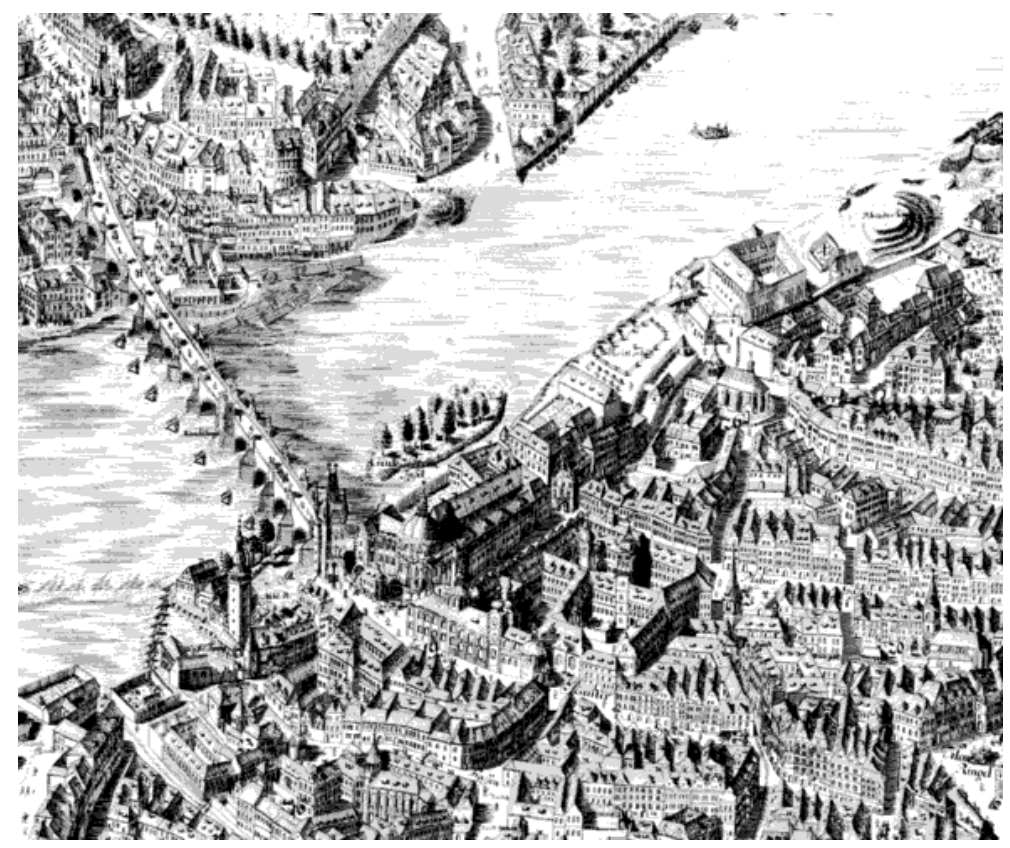

Fig. 5 Josef Daniel Huber, orthographic drawing of the Old Town, ink drawing, 1769. 


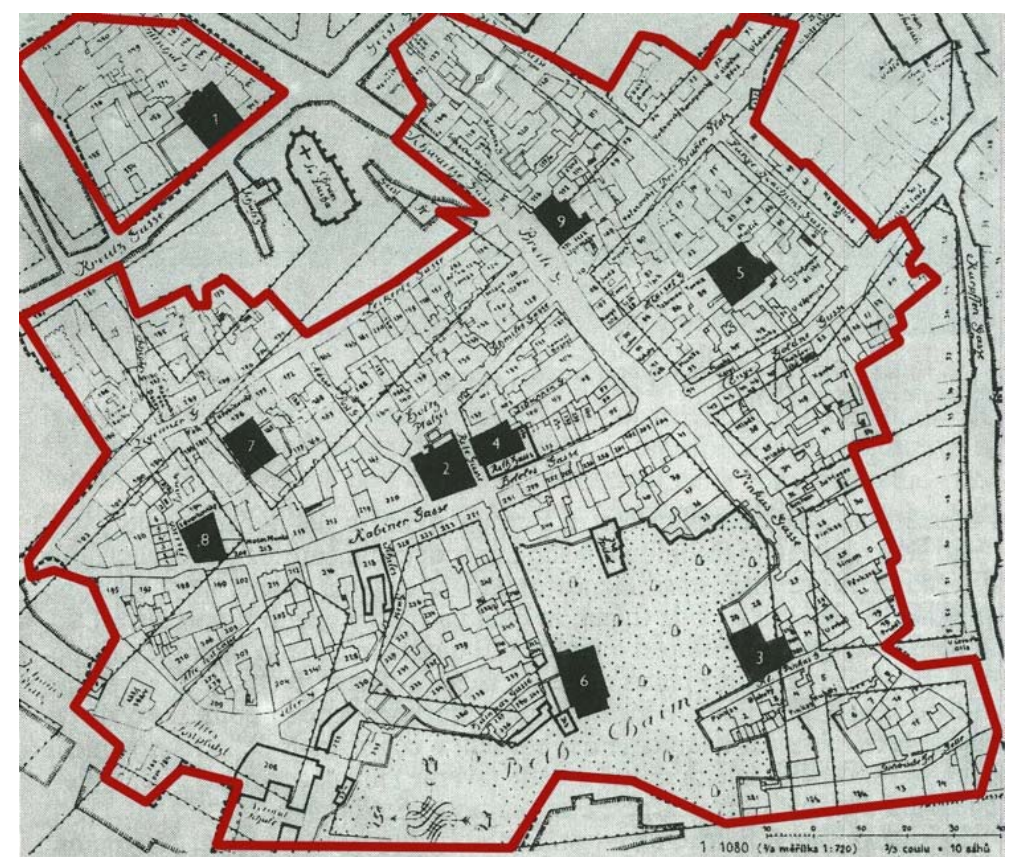

Fig. 6 Plan of the demolitions in the Jewish Town in 1895, with the Synagogues (1: Old School (Synagogue Španělská); 2: Staronová Synagogue; 3: Pinkas Synagogue; 4: High Synagogue; 5: Maisel Synagogue; 6: Klaus Synagogue; 7: Synagogue Cikánova; 8: Synagogue Velkodvorská; 9: New Synagogue).

The rise of National Socialism, with its well-known tragic events, marks the destiny of the Josefov island: all Jews were deported and exterminated in the death camps.

The preserved parts of the old quarter can be identified through a few isolated worship places. From the Old Town Square, you will arrive at Josefov, passing St. Nicholas Church and moving along Pařǐžská, a wide street designed in the 1893 reform project that leads towards the Vltava River.

Along this axis, at the intersection with Maslova Street, sits the oldest building in the district: the Old-New Synagogue (Staronová Synagogue). This synagogue is one of the surviving structures from before the 1893 transformation.

Perhaps due to the myths that surround this building - one legend says that the synagogue was built with stones from the Temple of Jerusalem, while another says that it was already built but buried and only later a rabbi showed its position to the Jews - the Synagogue is partially below the street level.

A little further on is the Old Jewish Town Hall, with an unusual clock, whose hands turn counterclockwise; hours, in fact, are marked by the Hebrew alphabet letters that are read from right to left. Continuing along Široká we approach the Jewish Cemetery, the only green place available to the Jews during the long centuries of isolation.

To access the Cemetery (židovský Starý hřbitov), you must pass through the Pinkas Synagogue (Pinkasova Synagoga), which today is the memorial to the 77,279 Czech and Moldavian Jews exterminated by the Nazis in the death camps.

The Cemetery, decadent in its appearance and the oldest preserved Jewish cemetery in Europe, is one of the most representative monuments of the community.

The gravestones are piled one upon the other due to the lack of space allotted for burial. There was no possibility of exhuming the graves, as in Jewish culture, this is considered an act of true sacrilege.

The oldest tomb is that of the rabbi and poet Abigdor Ben Isaac Kara, dating back to 1439. The last is from 1787 when Joseph II permitted burial outside. The most important tombs are indicated with signs, and among all of them stands out that of Rabbi Löw, Kabbalist and creator of the Golem. 


\section{The Reasons for Research}

In order to intervene in the historic sites of a city, it would be necessary to recognize in the history of the city's settlement some constants which are able to take on, in the complexity of the architectural phenomenon, some areas of knowledge that are not strictly architectural.

This operative survey is important to find some authentic reasons and operational standards for the intervention in the historic sites of the city and be able to transform them physically, through interventions that can restore in a unified way the relevant phases in the evolution of the urban settlement.

According to this premise, the settlement history most certainly plays a prominent role. Of course, this study does not take into account only the urban history in a strictly disciplinary sense, but rather the multiple areas of knowledge that have interfered with the physical structure of the city. The role of the history, in this case, is interpreted not as an allusive component, but rather as a structural impetus in urban design. In this respect, it is necessary to proceed in a rigorous and selective way in evaluating all the tools that the history of the city can provide for the architectural project.

First, a reliable working tradition must be identified in the historical development of the city-a working tradition within which a conscious manifestation of architectural design has always occurred, and which has sought to critically historicize the architectural project.

The goal is not just to activate that attitude on the theme of memory itself, in the sense of understanding the concept of history as a free repertoire of forms to imitate. On the contrary, in order to regenerate a critical dimension that the project assumes in the connotation of a possible transformation of the physical environment, it is necessary to abandon the condition of arbitrariness and make a real operation of historicizing considering all essential resources of the context.
This operation is designed to capture both the contradictions and the opportunities of history. Taking on a historical dimension means taking on the responsibility towards the past and tradition no less than towards the present and the future.

Rediscovering the sense of an island settlement in the city of Prague, dammed within the closed confines of the assigned jurisdiction and unique to that community, separated from the rest of the city, means recognizing not only an internal history of the Jewish ghetto as it has been structured through time, but above all, returning the external history which influenced the ways and discontinuous evolution of the whole city.

This marginalization of the Jewish ghetto in Prague, despite the physical separation from its urban surroundings, has established a physiological dependency on the arrangement of the "cities" of Prague, albeit its administrative autarchy.

Reconsidering the morphological structure and typological island of the ghetto, in the more general evolution of the city of Prague, does not mean necessarily managing some arbitrary reconstruction able to return the form, more or less conventional and stylized, which belonged to the ancient structure of the Jewish quarter. It is taken for granted that this attitude may lead the design project to interpret history as a repertory of forms and languages that, although contextualized in their original location, can be arbitrarily considered architectural standards from which to draw according to subjective individual tastes.

On the other hand, it does not mean either to celebrate the myth of history through the lucrative poetic around individual episodes, resulting in a close identification of the subject of the project with its past.

This procedure does not differ, at least on a purely logical level, from some historical agnosticism attitudes of apathy toward the past. Such attitudes in similar contexts can produce architectural objects that conceptually possess the ambiguous allure of high 
design but that, in the long run, are translated into a voiceless presence, a pure sign without meaning.

Alternatively, in these places settled by a history of deep cultural value, it is necessary to reconnect the moment of design to that of knowledge - especially in these moments and situations such as the old neighborhood of the Jewish Ghetto, where the arrangement of the urban structure is hardly recognizable after the demolition of the walls and the perversion of its design, and where the social and cultural identity persists regardless of the transformation of the place.

It is in this sense that the principles of historical formation are investigated here: principles of historic formation that are placed at the center of the design of individual episodes, still recognizable in the evolution of the context, and starting from the typological dimension as it relates to the morphological structure of the whole city and to the structural characteristics of the territory. This task is potentially prepared to carry contributions both from inside its evolution and from outside its context, in order to regenerate a united path that, even if discontinuous and erratic, is nevertheless able to propose intents cognitive of reality and return them to architectural design.

An essential component of such an attitude is the demand for a research that recognizes, partially and also subjectively, the importance of urban facts invariant in the evolution of the city.

These persistences, regardless of philological rigor, are to be found not only in the evolution of the physical structure of the city, but rather in the social and cultural operations, with the unified aim of a system of sharing between the economy and production, for example, or between culture and social emancipation.

It concerns, for instance, the hierarchical arrangement of collective and representative structures of the ghetto, located and protected in strategic areas of the settlement. This location was able to interact with the users' behavior, with respect to their habits in going to their places of worship, or with respect to the needs to use social or health service facilities, or to the rituality of attending educational establishments.

It also concerns a strategic arrangement of the individual activities, stratified into building structures, which occupied the space through a layout that provided the maximum accessibility to public and commercial activities, located on the ground floor, while the more private activities were housed on the upper floors of the buildings.

Finally, it concerns the interpretation of the difficulties generated by the urban density and thus the shortage of space. That situation was mitigated through a principle of cyclic substitution of the functions, for which the occupation of the individual spaces occurred as an interchange of activities, some to be carried out during the day and others in the night depending on the different productive, social and even cultural needs.

These considerations go beyond the characters of the individual architectural episode. In the conception of the city as an artifact, as a work of art, they impress a particular significance on the individual structures, which exceeds the physical dimensional and figurative limits to give back a unified value symbolically extended to the whole city.

The urban analysis is still one of the most powerful instruments in recognizing a unified framework for the design elements. However, it still has the limitation of having to measure its actions against standards internal to its investigation, by taking elements of continuity or permanence, through the selection and sometimes the analogic repetition of the explored physical facts.

Conversely, the survey proposed here is more complex and extensive, and the case in question, although limited, proves this point. In this specific research area on the island of the Prague Jewish ghetto, there are wide convergences, ranging from human geography to local history, from the social sciences to the economy, to the history of architecture and even 
up to the myth.

The mythological construction of the Golem, as the legend of the Philosopher's Stone-symbol of alchemy, able to heal the corruption of matter-has been more effective in the evolution of the Jewish ghetto that many other structural influences.

This mythological construction has deeply affected the individual and collective behavior of the ghetto community, as well as the physical construction of its space and rituals in its places of worship, although it is not scientifically accepted by the rational exploration of urban history.

In this experimental reconstruction of the island of Jewish Prague, we have proposed to evaluate, with this contribution, the intention to regenerate through single episodes an image of the lost city, which is perhaps no more possible to find in its unity, but which is possible to evoke throughout single existing and planned episodes, that belong above all to its myth.

\section{Method of Work}

This introduction allows us to explain how the approach to the theme of the project has followed a well-defined working structure. It was built starting from the analysis of the problem and its specific issues.

In our specific study case, this problem is represented by the proposed design theme: the attempt to assert the strong historical and cultural identity of Josefov by recovering dismissed areas identified within the urban fabric of the historic neighborhood.

This theme is also an opportunity to consider the whole urban design of the entire neighborhood, from a viewpoint that also involves a reorganization of some functions and the reinforcement of others.

The research was carried out with the aim of developing some suggestions at the urban and the architectural scale. These suggestions act as an example of how to face the design theme, of recovering identity in Josefov through the re-use of small, dismissed areas within its fabric.

The planned scientific activities were organized into different phases and divided by specific tasks.

A first phase of the work involved the collection and study of information regarding some important architectural resources on the context. This step was supported by research and analysis of cartographic, iconographic and bibliographic materials, which allowed us to explore aspects concerning the urban history, the structure of the settlements, the particular context of the application and its physical characteristics.

This survey was followed by the preparation of thematic maps that allowed us to identify, in significant historical sections, past transformations of the neighborhood's urban fabric and the various phases of human settlement within its confines.

This first step had the aim of organizing a database of information that reveals the characteristics of the entity that is Josefov, a phenomenon within the city of Prague.

A second phase of the work has involved an investigation on site in order to identify the settlement structure of the neighborhood and, in particular, to identify the existing conditions (for example, the physical context, zoning, the main facilities and public buildings, and accessibility). This investigation allowed us to discover the potential of the place, its physical characteristics, its settlement structure and its particular aesthetic character.

This survey was followed by an analysis of the potential project areas that could be reused (distinguishing between those still operating and those dismissed), and the formulation of hypotheses for a possible functional re-organization or the definition of potential new uses.

In order to produce a functional layout for urban regeneration projects, this second step was intended to focus on the instruments and intervention criteria to be taken during the design process for each individual project area, according to the existing conditions (for 
example, the grafting of a new structure on an existing one, replacing a part of it or the whole structure with new activities).

\section{Results}

The adopted strategic choices allowed us to identify small areas inside the Josefov Quarter, which proved to be suitable to the application of our research.

Each of these places poses related questions, for example, due to the following characteristics:

- Morphology (unused areas along the infrastructure that crosses the neighborhood or in close relationship with important communications such as streets, rail- and waterways, such as the "Moldava" River);

- Representation (most selected areas are found within a residential zone);

- Architectural character (these are areas that belong to the historic urban fabric of the neighborhood).

The possible points for intervention are located in two open areas adjacent to the St. Agnes convent (Klášter Sv. Anežky České), between Kozi Street, U Milosrdnýche Street, na Františku Street and next to the Vltava River. The first is temporarily occupied by outdoor sport equipments and a parking area, while the other is completely free.

Continuing along Dvořákovo Nabrezi, along the Vltava river, another open area adjacent to the na Františku hospital is located between the streets Dusni and U milosrdnýche. Finally, a fourth area is situated next to the Staronová Synagoga between the Parizska Street, Brehova Street and Maiselova Street in the heart of the old ghetto.

Having defined these potential points of application, it is now necessary to make clear the role of architectural design within this framework. Most importantly, it is necessary to understand how the architectural project can work to promote the identity of the "urban island"-at this point only theoretically identifiable in Prague's urban fabric.
The answer to these queries may be found in the notion of a conceptualization of architecture that, independent from individual representational options, is able to leverage its iconic nature and act as a work of art that is linked to memory.

This critical attitude towards the project has often inspired content and forms derived from a cultural context, in which forms have taken on a symbolic value (iconological or iconographic).

It often occurs that in particular contexts and in a given historical period, the permanence of symbolic elements interacted positively with the artistic and architectural results.

In other words, architectural culture, (at least that which considers the urban context as a positive resource), has historically adopted a critical methodology. This method goes beyond referencing direct sources and takes on an experimental approach that is less empirical and more intuitive, influenced by perceptions, in order to arrive at an interpretation of a possible reality.

The difficulty of this specific case study, Prague's Josefov district, is the total absence of concrete historical references, with the exception of small yet famous instances. These surviving structures are able to reveal only a virtual existing environment, shaped by very few enduring relics that show the volatile historic and symbolic nature of the area.

In other words, this island is striking due to its absence.

It is not just the "physical" absence, a "material" absence but also an "immaterial" one-an absence related to the neighborhood's lack of elements tied to culture, identity, tradition and society.

In this particular aspect, architectural design can play a role in trying to make these absences present, bringing the project to a conceptual threshold, returning a form of critical awareness to the relationship between historic and new construction.

A second issue concerns the potential of the dismissed sites identified within these "urban islands", 
and the way they should be re-thought to once again give identity to the context.

This second aspect is more related to a certain creative attitude, an experimental architectural approach that is distinctly clear and direct in comparison to the strategy of simple preservation but using a more complex design approach. This approach aims to enhance not only the single historical monument or building, but also the entire context. It is a strategy that induces a historically perfect reconstruction but that is limited by the contradictions of a false historical reconstruction.

We have already seen this type of experiment, especially after the Second World War when many European cities such as London, Berlin, Dresden, and Warsaw, seriously damaged or completely destroyed, used the uncritical, conservative principle of "where it was, as it was" to guide their reconstruction.

The anxiety to preserve - or even to recreate - the destroyed heritage was so strong that it led to exact and artificial replicas of that heritage: a kind of manufactured and "in vitro" creation.

In the case of Prague, however, there was interest in the circumstances of architectural research. This led to an approach that became concrete not through linear derivations of the act of composition-from the design of the architecture according to the typological model, to the definition of the details - but through discontinuous progressions, dialectical inductions, and even through intuitive actions that have no certainty and no evidence, but that reconstruct an image mediated by an allegorical and metaphorical code.

Thus this is not simply about a figurative aspect, but also about a program of activities and strategic functions that have the aim to regenerate the original identity of the urban culture of this part of the city.

The third and final point among the questions raised by this study concerns the preservation of the various cultural identities in the city.

In general terms, the expressions of diversity—social, economic and also cultural-have contributed to the historical formation of a heterogeneous community in which autonomous and historically independent settlements have each become carriers of a local tradition. These can still be recognized today inside the city, in its various neighborhoods, and in its various urban areas.

The goal of this work is to verify, case by case, how to make it possible that the architectural forms become a symbol (tool) in an advanced management of the city.

This settlement strategy (even through small structures in secondary areas) is started through the dislocation of particular typological-functional structures. These structures must be able to creatively combine new behaviors and figurative innovation, in order to counteract the homogenizing territorial and cultural processes typical of the post-reconstruction and post-economic boom periods.

The aim of this research is to preserve and recognize the cultural identity of the Jewish community within the city, using a specific strategic vision that begins with the reconstruction of these cultural remains and the recovery of small urban fragments, within and on the edges of this urban island.

\section{Conclusions}

The importance of this method is the consideration of the practice of composition as a slow and careful approach, starting from the place where it takes shape, through a continuous progression, in order to find the appropriate features of the architectural space.

Space is perceived as a sensitive experience, able to stimulate the meaning and the essence of the architectural experiences.

The architectural project, in this sense, becomes an important object of knowledge and a real creative act. The result of our research is the set-up of a procedure that has as its main objective an experimental design method, working according to the resources of local context and considering an idea of urban regeneration.

An architectural project is a physical fact within the 
city.

Architecture itself is a physical fact, because it has a structure that makes it different from the other artistic practices (for example, painting, sculpture, cinema, music, and so on) and its responsibility is significant, as a design project not only influences spaces and contexts within the city but at the same time is itself influenced by historical, cultural, social and, not least, architectural experiences that have characterized the place in which it is found.

\section{References}

[1] Peretta, R. 1997. "Sei Città, Almeno.” Abitare 363 (June). (in Italian)

[2] Sanguin, A. L. 1997. Vivre dans une île. Une Géopolitique des Insularités. Paris Montréal: L'Harmattan. (in Frech)

[3] Merler, A. 1990. "Insularità. Declinazioni di un Sostantivo.” Quaderni Bolotanesi 16: 155-64. (in Italian)

[4] Ripellino, A. M. 1973. Praga Magica. Torino: Einaudi. (in Italian)

[5] Janouch, G., trans. 1971. Conversations with Kafka. New York: New Directions Publishing. 